\title{
CLUB MOTORCYCLE RACING MEDICAL AID AND TYPES OF INJURY
}

CAPT G R PARK, MB, ChB, FFA, RCS, RAMC(V)

205 (Sc) General Hospital, RAMC(V)

SUMMARY: The way medical aid is provided at motorcycle club race meetings and the types of injuries seen is presented and discussed. Significant differences exist in the pattern of injury seen between riders of solo and sidecar machines. Few lower limb injuries occur because collisions with a second vehicle are rare.

\section{Introduction}

In 1974205 (Sc) General Hospital (TA) was approached by the Melville Motor Cycle Club for medical aid at their race meetings. These meetings take place approximately four times a year in Spring, Summer and Autumn. They include one practice meeting when racing does not occur. Both sidecars and solo machines race. All the track events are subject to the Royal Automobile Club rules. All events count towards the Scottish Championship.

The track (Fig 1) is a World War II Aerodrome situated 22 miles from

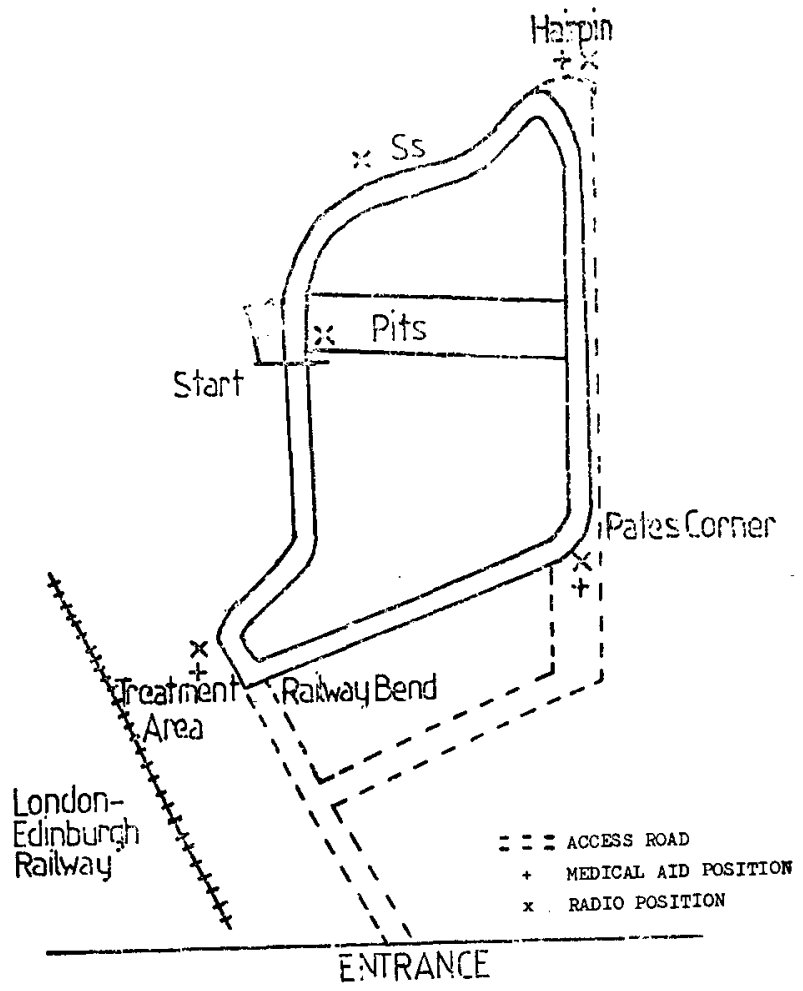

Fig. 1 East Fortune Race Track 
Edinburgh. It is 1.85 miles in length. The track record for a solo machine is $93.4 \mathrm{mph}$ and for sidecar combinations $88.2 \mathrm{mph}$. Speeds in excess of $120 \mathrm{mph}$ have been recorded using radar. All traffic using the track at any time during a meeting must obey the marshall's instruction and travel in a clockwise direction.

Communication is provided by 104 Field Squadron, Royal Engineers (V) using A41 radios at the following points: Pits, the S's, Hairpin, Pates Corner and Station Bend (Fig 1). This enables the whole track to be seen by the radio operators.

\section{Personnel}

\section{Personnel and equipment}

The following personnel are usually required: one Medical Officer (MO); two Nursing Officers (NO); three Corporals (CPL) and Sergeants (SGT); five Medical Assistants (MA) II and III; two Cooks and four Drivers.

\section{Equipment}

Three Landrover ambulances; one 4 ton truck; medical officers equipmentsimilar to that described by Aston ${ }^{1}$; treatment area equipment-sufficient to deal with minor injuries and short periods of observation; three non-commissioned officer first aid packs and two $60 \mathrm{lb}$ tents.

\section{Deployment}

A treatment area is established in a $60 \mathrm{lb}$ tent which enables minor dressings, stitching, short period observation and documentation to be performed. It also acts as a storage area for spare dressings etc.

For four years the treatment centre area was established near to the pits. This however gave rise to two problems. Firstly the casualty was brought to the treatment area and assessed. It was then extremely difficult to evacuate them because no ambulance was based at the pits and all movement on the track had to take place in-between races. Secondly, it became increasingly difficult to keep members of the public out of the treatment area when a casualty arrived. It was however conveniently near to the snack bars and toilets. In 1978 it was decided to move the treatment centre and associated personnel to the Station Bend. This was better because it allowed easy access, evacuation of casualties during races, and almost complete privacy. Personnel visit the pits in small groups either on foot or on one of the track vehicles. One ambulance is based here.

Two small groups comprising one SGT or CPL, one MAII or III and one driver with an ambulance and first aid pack are sent to the Hairpin and Pates Corner.

The Medical Officer sees all injuries sustained during racing. He is usually based at the treatment area but has all the equipment for resuscitation in his car or Landrover. If any person is seriously injured, unconscious or sustains a long bone fracture the MO will see them on the track. This enables treatment such as analgesia and splinting to be carried out at the site of the accident and 
prevents further suffering and delay at the treatment area. The Medical Officer only, is allowed onto the track during a race in the event of serious injury. If the track is completely blocked the race will be stopped. This is fortunately rare. Nursing Officers are based at the treatment area with the MO.

\section{Documentation}

A simple register is kept of all injuries and all patients referred to hospital have a modified version of the F Med 26 completed.

\section{Injuries}

Only injuries referred for hospital treatment are considered. Minor injuries needing simple first aid are numerous.

The nearest hospital is Roodlands Hospital, five miles away, and all injuries are sent there. Because of the nearness of this hospital less is done in the treatment area than normally would be the case. Unfortunately only records for the years 1978 and 1979 are available because records prior to that were destroyed accidentally. During this period there were eight meetings resulting in 26 injuries in 23 patients. Seventeen of the injured rode solo machines, five rode sidecar combinations and one was injured in the pits whilst repairing a machine. Injuries to sidecar passengers and drivers are not differentiated.

The types of injuries sustained are shown in Table I. Fifty per cent of all

Table I

Injuries received during motorcycle racing

\begin{tabular}{|c|c|c|c|c|}
\hline Type of injury sustained & $\begin{array}{l}\text { Total No } \\
\text { of injuries }\end{array}$ & $\begin{array}{l}\text { No of injuries } \\
\text { from solo } \\
\text { machines }\end{array}$ & $\begin{array}{l}\text { No of injuries } \\
\text { from sidecars }\end{array}$ & $\begin{array}{c}\text { Other sites } \\
\text { injured }\end{array}$ \\
\hline $\begin{array}{l}\text { Unconscious } \\
\text { Lower limb injury } \\
\text { Upper limb injury } \\
\text { a. Dislocated shoulder } \\
\text { b. Fractured clavicle } \\
\text { c. Fractured humerus } \\
\text { d. Forearm injury } \\
\text { e. Hand injury } \\
\text { Fractured pelvis } \\
\text { Head and neck injuries }\end{array}$ & $\begin{array}{r}6 \\
4 \\
13 \\
\\
\\
\\
\\
1 \\
2\end{array}$ & $\begin{array}{cc}2 & \\
4(1) & (2) \\
10 & \\
& 3(4) \\
& 2 \\
& 1 \\
& 2 \\
& 2 \\
0 & \end{array}$ & $\begin{array}{ll}4 & \\
0 & \\
2(3) & \\
& 0 \\
& 0 \\
& 0 \\
& \\
& 1 \\
& 1(3) \\
1 & \\
1(5)\end{array}$ & 1 (pits) \\
\hline Total number of injuries & $26(6)$ & 17 & 8 & 1 \\
\hline
\end{tabular}

Notes: (1) Includes one traumatic amputation of foot. (2) Includes two fractures of tibia and fibula. (3) Includes one traumatic amputation of fingers and thumb. (4) Includes one axillary nerve palsy. (5) Includes one burnt neck following radiator explosion. (6) Several competitors sustained more than one injury.

injuries involve the upper limb. Most of these were sustained by riders of solo machines. No injuries above the elbow were sustained by sidecar machine riders. Four hand injuries (17 per cent) were sustained. The most severe was sustained by a sidecar rider who amputated three fingers and a thumb when his hand was pushed through the spokes of a wheel. Surprisingly, in view of the use of compressed air tools, only one hand injury was seen from the pits and no eye injury. Fractured tibia and fibula was seen in two patients. 
Six patients (26 per cent) sustained concussional head injuries involving transient loss of consciousness. Sidecar riders are more likely to suffer this type of injury.

The average age of all injured riders was 24.5 years (range 17-44 years). For solo riders it was 24.3 years (range 17-44 years) and for sidecar riders the average age was 25.6 years (range 20-34 years). These differences are not significant in this small group.

The number of injured riders travelling less than and more than fifty miles is shown in Table II. Thirteen competitors living more than fifty miles from the track were injured of whom six (46 per cent) required admission. Ten competitors living less than fifty miles away were injured of whom four ( 40 per cent) required admission.

Table II

Number of competitors injured who had travelled less than or more than 50 miles

\begin{tabular}{lcc}
\hline Competitors injured & $\begin{array}{c}\text { Number of injured competitors living } \\
\text { More than 50 miles } \\
\text { from the race track }\end{array}$ & $\begin{array}{c}\text { Less than 50 miles } \\
\text { from the race track }\end{array}$ \\
\hline Total number of competitors injured & 13 & 10 \\
Total number requiring admission to hospital & 6 & 4 \\
Solo riders requiring admission to hospital & 3 & 4 \\
Sidecar riders requiring admission to hospital & $\mathbf{3}$ & $\mathbf{0}$ \\
\hline
\end{tabular}

\section{Discussion}

Several studies have looked at the pattern of injury of riders involved in road traffic accidents ${ }^{2-5}$ but the pattern of injury during club racing differs significantly from this (Table III). The pattern of limb injuries is reversed with upper limb injuries predominant. Concussional head injury is commoner. Reasons for this include the strict rules governing racing, the absence of motorcars, and sidecar injuries.

\section{Table III}

Comparison of injuries between this and other studies

\begin{tabular}{lccc}
\hline \multicolumn{1}{c}{ Author } & Lower limb injury & Upper limb injury & $\begin{array}{c}\text { Concussional head } \\
\text { injury }\end{array}$ \\
\hline Andrew 1979 & $30 \%$ & $31 \%$ & $6 \%$ \\
Drysdale et al 1975 & $31 \%$ & $22 \%$ & $19 \%$ \\
Br Med J & $70 \%$ & $\overline{50 \%}$ & $\overline{23 \%}$ \\
This study & $15 \%$ & & \\
\hline
\end{tabular}

Strict rules governing racing are laid down by the Royal Automobile Club. All competitors must wear either jet or full face crash helmets and protective leather suits and gloves. These afford a lot of protection ${ }^{5}$. All riders must hold 
a full driving and racing licence ${ }^{5}$. They are more experienced and older than those involved in road traffic accidents. There are few injured aged between 15 and 20 years when 60 per cent of all road traffic accident victims are injured ${ }^{2}{ }^{5}$. Alcohol consumption is not allowed.

No other vehicles are allowed on the track during racing, and collisions are with stationary objects, which account for only 5 per cent of road traffic accidents". There are no side entry points to the track so the "crossroad" type of injury does not occur ${ }^{6}$, and this is one of the reasons why injuries to the lower limb are uncommon. The only lower limb amputation was caused during a. practice race when a side entry onto the track is allowed, and a relatively inexperienced competitor failed to filter into a bunch of motor cyclists on the track. His left foot was caught between the foot rest and another motor cyclist and amputated.

Sidecar machines are driven so that the rider and passenger adopt a position which is parallel to and as near to the ground as possible (Fig 2). When involved

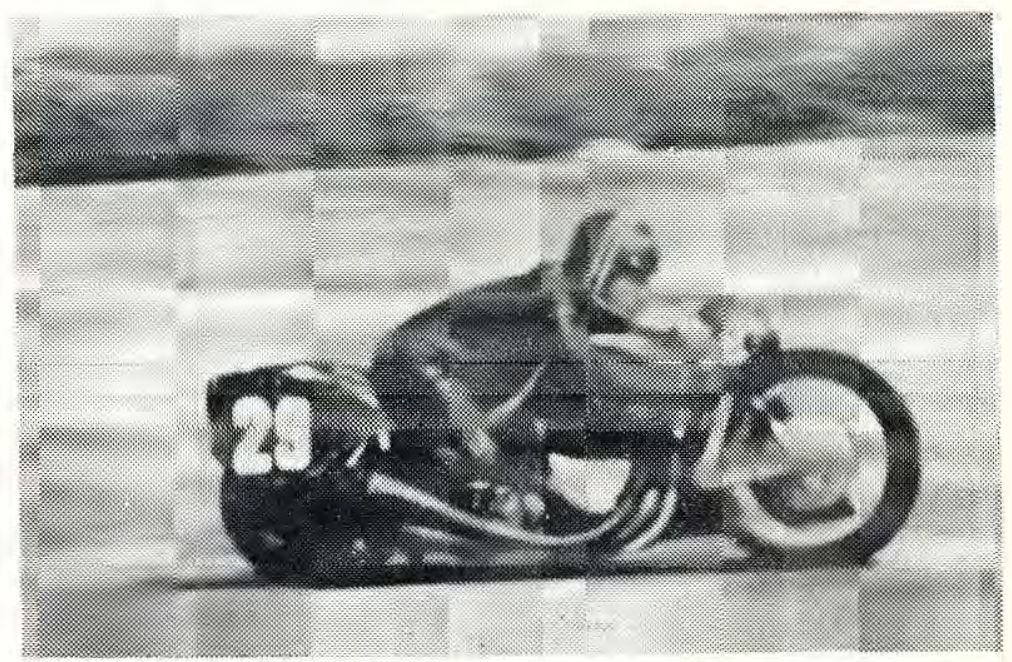

Fig. 2 Position adopted by sidecar riders during racing

in an accident both leave their machines in this position, usually with their arms by their sides. The force on the arm, if holding onto the machine, is one of pure traction without any abduction and may be the reason for the lack of injuries above the elbow. This position also explains why head injuries are more common as the head is the first part of the body to strike an object. Lower limb injuries will obviously be uncommon in this type of accident. Although the number of sidecar injuries is half that sustained by solo riders only 30 per cent of races involve sidecars and of all competitors only 20 per cent compete in sidecar races. The incidence of injury per race is therefore higher. When sidecar competitors are injured they tend to be injured more seriously.

Being part of a national championship many of the riders come from long 
distances. Often the competitors use their road machine to race on. Since local accommodation is not available they spend the night in a tent, and they are commonly unaccompanied. It is often impossible to send them home accompanied by a responsible adult, after injury and so, admission to hospital is required for minor injuries.

This study only covers a two year period. Before the study period there was one crowd incident when a motorcycle entered a spectator area and injured six adults and children. The medical team must be prepared to deal with more than one or two seriously injured people simultaneously. There has been one fatal head injury. Medical emergencies are rare because interest in this sport is usually by young people although epileptic, diabetic and cardiac emergencies have been dealt with in the past.

There are many benefits to a Territorial Army unit providing this type of medical cover. Practical experience in the management of injured patients is difficult to obtain during the training of MAs. Medical cover of this nature enables them to put into practice much of their classroom teaching. It is an extremely popular event, generating much enthusiasm within the unit. Recruiting is aided by being able to offer this type of medical cover and by spectators watching the races, frequently, seeing their local medical unit in action. Finally, many of the injured riders and relatives are grateful for our services and either write or thank us at the next meeting.

\section{Acknowledgements}

I would like to thank my colleagues who have participated during these meetings. The QA sisters have been especially helpful both in the training of MAs in the class room and at race meetings where they continue to teach MAs, often in unpleasant weather conditions. The Clerk of the Course, track marshalls and other organisers have shown considerable patience whilst we treat the injured motorcyclist and ensure our safety while this is happening.

\section{REFERENCES}

1. Aston, P. Equipment for use at Roadside Accidents. Br Med $J$ 1969; iv: 214-217.

2. Drysdale, W F Kraus J F, Franti, $\mathbf{C}$ E and Riggins, $R$ S. Injury Patterns in Motorcycle Collisions. J Trauma 1975; 15: 99-115.

3. DeAner, R M and FitchetT, V M. Motorcycle Trauma. J Trauma 1975; 15: 678-681.

4. Zettas, P and Thanasophon, B. Injury Patterns in Motorcycle Accidents. J Trauma 1979; 19: 833-836.

5. ANDREws, T A. A Six Month Review of Motorcycle Accidents. Injury 1979; 10: 317-320.

6. Special Correspondent. Motorcycle and Bicycle Accidents. $\mathrm{Br} \mathrm{Med} J \mathrm{1979}$; i: 39-41. 